\title{
Research on Urban Rail Train Passenger Door System Fault Diagnosis Using PCA and Rough Set
}

\author{
Lin Shuai ${ }^{1}$, Jia Limin ${ }^{*}, 1$ Qin Yong ${ }^{1}, \mathrm{Yu} \mathrm{Bo}^{2}$ and Wang Yanhui ${ }^{1}$ \\ ${ }^{1}$ Beijing Jiaotong University, Beijing, 100044, China \\ ${ }^{2}$ Locomotive and Car Research Institute, China Academy of Railway Sciences, Beijing 100081, China
}

\begin{abstract}
Train passenger door is the key system for operation and maintenance of urban rail train. In this paper, working process of the passenger door system of urban rail train is analyzed and the mathematical model is established. Firstly, the method of parameter estimation is used to obtain physical parameters of doors in different working conditions. Then fault diagnosis experiment is carried out on train passenger door with principal component analysis and rough set theory. In the end, fault diagnosed accuracies under different time settings of opening and closing profiles with the test rig are verified.
\end{abstract}

Keywords: Door control system, Fault diagnosis, Principal component analysis (PCA), Rough set.

\section{INTRODUCTION}

With increasing operation tasks, passenger congestion occurs during peak time, and extrusions and manhandling on the door affect doors' normal working process, which causes fault to the door resulting in train's delay eventually seeking rescue. The way to improve operation efficiency and quality of urban rail train by using real-time data is a big issue for metro operation department. Door system is one of the most frequently damaged systems on urban rail train while the passenger doors are the main objects of complaint for maintenance personnel due to their large size and high frequency utilization.

All along, the domestic and foreign scholars' research has mainly been focused on analysis through historical data, however this method lacks real-time factor and is ineffective. The studies on urban rail trains' electric doors are limited to the reliability analysis due to real-time data acquisition difficulties and usually methods such as reliability block diagram, bias methods, fault tree network [1, 2], GO [3] and FMECA [4] are used. The applications of these methods require a vast amount of prior knowledge which do not make full use of the state data real time train operation, therefore these are not feasible to new train lines or new models of equipment. Migueláñez \& Lehrasab [5, 6] proposed a dynamic neural network fault diagnosis method for the pneumatic door. Dassanayake [7] proposed a parameter identification method for vehicle door motion state. Motor inductance, resistance and other parameters were estimated to guide the diagnosis of the door system, but this method has been more applicable to the door system as a fault review (Table 1).

The traditional fault diagnosis methods of pneumatic door are often limited to vehicle opening and closing time

*Address correspondence to this author at the Beijing Jiaotong University, Beijing, 100044, China; Tel: 86-13901064639; E-mail: jialm@vip.sina.com
[8]. The modern urban rail train passenger doors use closed loop control principle and fault information is difficult to judge from significant information under the closed loop control of EDCU (Electronic Door Control Unit) as motor voltage; moreover, in modern urban rail train passenger doors, current as well as the identification of opening, closing time and so on are determined. The real-time working data is restored in the EDCU, which can be transmitted to the fault diagnosis computer through MVB. Based on the urban rail train passenger door working model, parameter estimation based on EDCU data can be conducted to check if there are sudden changes as the fault occurs. Then the time domain analysis method is used for the fault isolation experiments, and under different working conditions and configurations, the accuracy of this method is verified.

\section{ANALYSIS AND MODELING FOR URBAN RAIL TRAIN COMPARTMENT DOORS}

\subsection{Analysis of Urban Rail Train Doors Working Process}

The working mode of urban rail train doors is quite similar to ball screw table and gear drive and the structure of the main working parts (door suspension) can be simplified, as shown in Fig. (1).

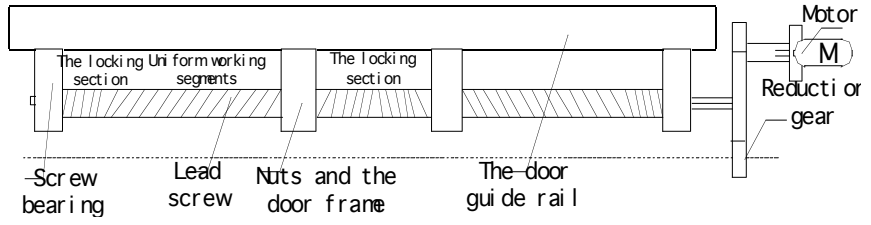

Fig. (1). Simplified view of urban rail train passenger door.

Open/close commands are sent by drivers loading the open/close button in the cab. TCN transmits control signals to electronic door control unit (EDCU) while EDCU starts the motor and drives the screw in a preset delay. 


\subsection{Passenger Door Model Symbols Definition}

Table 1. Parameters of passenger door model.

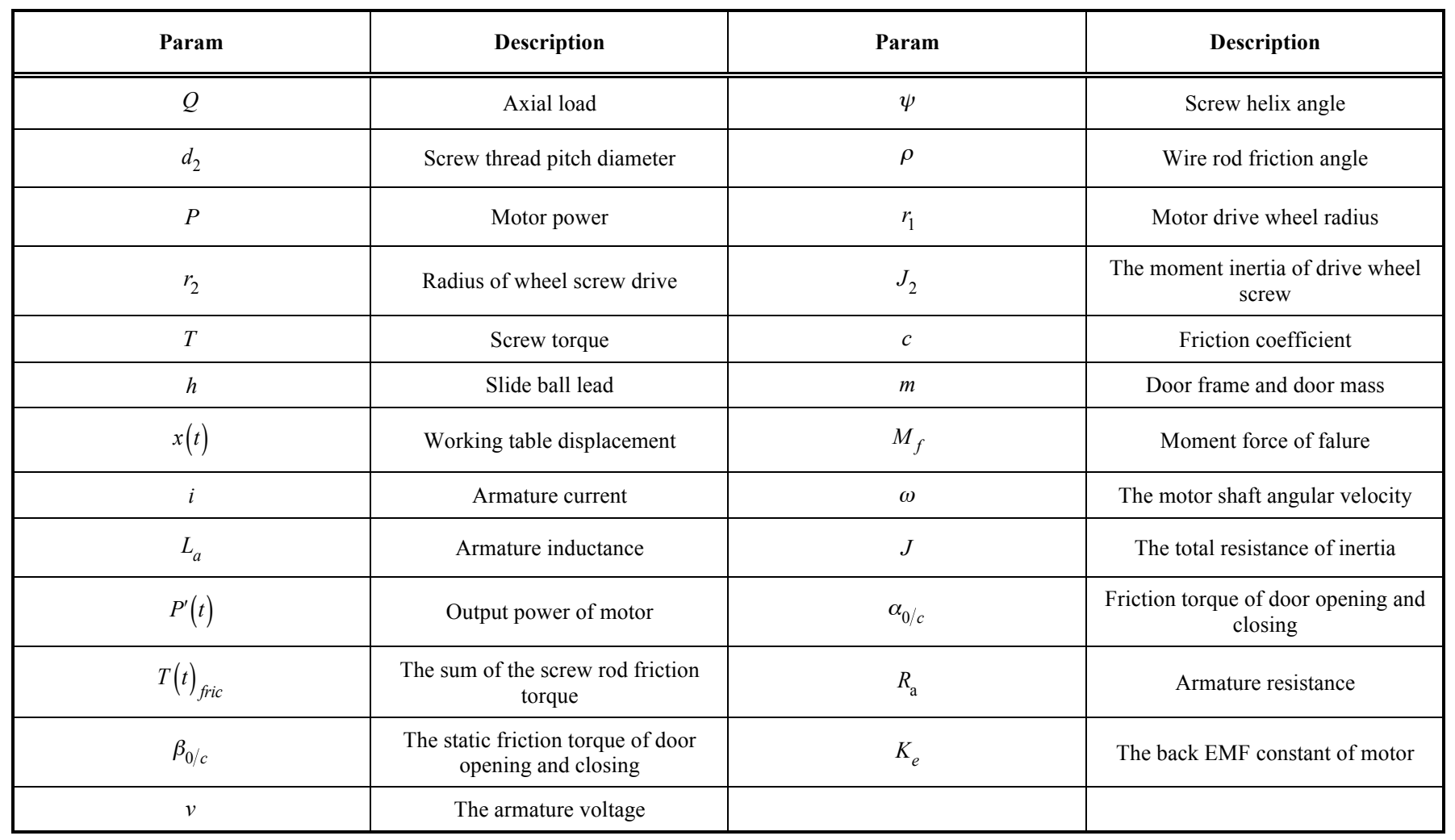

\subsection{Urban Rail Train Passenger Compartment Door Model}

As shown in Fig. (1), the train compartment doors of wire rod are divided into two parts and screws rotate in opposite directions, respectively, for opening and closing the left door leaf. The screw rod of each part is divided into three sections, respectively, working section with helix angle greater than friction angle, locking section with helix angle less than the friction angle, and the transition section between the two. A typical portal velocity is shown in Figs. $(2,3)$.

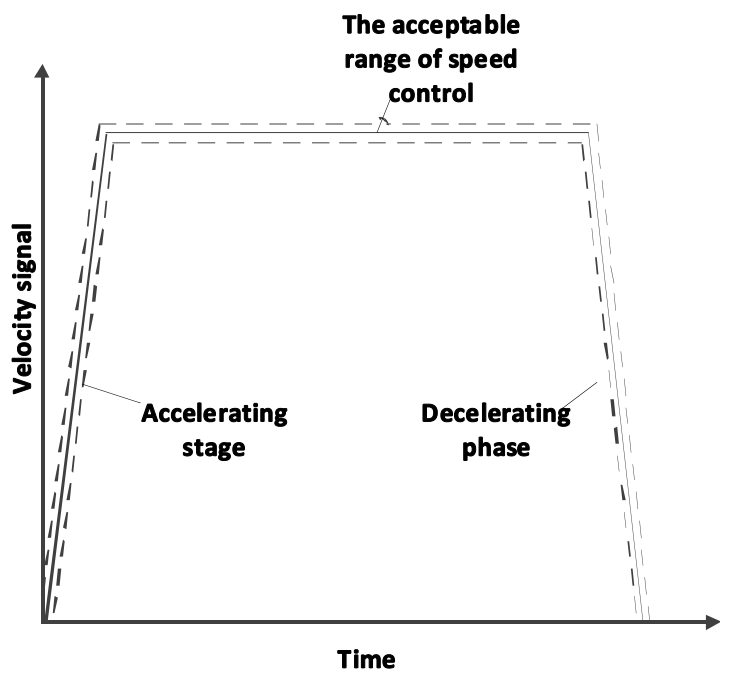

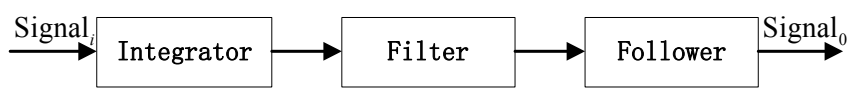

Fig. (3). Diagram of basic simulation integral circuit.

Electric door opening and closing speed can be adjusted in the system between 2.5 and 4 seconds by the train control system. Each motor shaft is provided with a high resolution optical encoder. Optical encoder can measure the displacement and rotation of the motor, the door position acquisition, optical encoder and EDCU having closed-loop control door which opens and closes the door, so judging the door fault only from the working time is not feasible.

Actually, there is a difference between short and long operation mode in running time and running speed, but the working distance, namely graph covering trapezoidal 3 in the area, is the same.

According to the Darren Bell principle, sliding screw working torque can be described in formula (1) [9]:

$$
T=\left[J_{2}+m\left(\frac{h}{2 \pi}\right)^{2}\right] \frac{d^{2}}{d t^{2}}\left[\frac{2 \pi}{h} x(t)\right]+c\left(\frac{h}{2 \pi}\right)^{2} \frac{d}{d t}\left[\frac{2 \pi}{h} x(t)\right]
$$

Considering the axial load and failure caused by the torque, we can get

$9550 * P^{\prime}(t) / 2 \pi \omega(t)=\frac{r_{1}}{r_{2}} T+Q \tan (\psi+\rho) d_{2}+M_{f}$

Fig. (2). Door speed trajectory diagram. 
If the motor is taken into consideration, although there are many non-linear factors to motor running state, according to the linear theory of localization [10], the impact on the result of the nonlinear facts can be ignored. When the doors open, the friction force impacts on the operation of the joint between each component and motor rotary inertia, so the electrical door model can be expressed as:

$$
\begin{aligned}
& v(t)=R_{a} i(t)+L_{a} \frac{d i(t)}{d(t)}+K_{e} \omega(t) \\
& P(t)=R_{a} i^{2}(t)+L_{a} \frac{d i(t)}{d(t)} i(t)+K_{e} \omega(t) i(t) \\
& P^{\prime}(t)=L_{a} \frac{d i(t)}{d(t)} i(t)+K_{e} \omega(t) i(t)
\end{aligned}
$$

This model shows that doors' roller guide slots, screw rods and drive nuts fail, affecting the motor load, motor rotary inertia and friction torque. Under the control of EDCU, the motor speed is kept stable but the motor driving torque and motor power increase or decrease, so the power ride's comfort changes. Power ride's comfort under different modes of door machinery fault shows different characteristics and the fault categories can be identified according to this principle.

During the working process, as it does not involve gravity acting, the motor output is mainly used to overcome the friction torque and the load. The model (1), (2) can be simplified as follows.

$J \frac{d^{2} \omega(t)}{d t^{2}}=K_{e} i(t)-T(t)_{f r i c}$

$T(t)_{\text {fric }}=\left(\frac{K_{e}^{2}}{R_{a}}+\alpha_{0 / c}\right) \frac{d \omega(t)}{d t}+\beta_{0 / c} d(t)$

$d(t)=\left\{\begin{array}{l}1, \text { Opening parameter } \\ -1, \text { Closing parameter }\end{array}\right.$

$J$ contains rotary inertia between motor and the motor rotor, door leaf, screw rod and nuts on the door. Indirectly from the inertia moment, the fault causes numerical changes of $J 、 \alpha_{0 / c}, \beta_{0 / c}$, therefore the changes of these values can directly reflect the fault influence on door.

\section{PCA BASED FAULT DETECTION}

\subsection{Signal Pretreatment of Urban Rail Train Doors}

In order to obtain concrete numerical values of $J 、 \alpha_{0 / c}$ 、 $\beta_{0 / c}$, collected data was used to conduct parameter estimation according to formula (3). For the convenience of treatment, system (3) can be transformed into:

$$
\begin{aligned}
& \frac{d^{2} \omega(t)}{d t^{2}}=\frac{K_{e} I_{a}(t)}{J}-\frac{\alpha^{\prime}}{J} \frac{d \omega(t)}{d t}-\frac{\beta_{o / c}}{J} d(t) \\
& \alpha^{\prime}=\frac{K_{e}^{2}}{R_{a}}+\alpha_{0 / c}
\end{aligned}
$$

On the basis of the input and output of passenger door system (i.e. formula (4)) of the continuous analog signal, integral filter circuit was used to conduct fast integral, and discrete digital signals output were used to carry out signal processing. Integral filter circuit's principle is shown in Fig. (4) $[11]$.

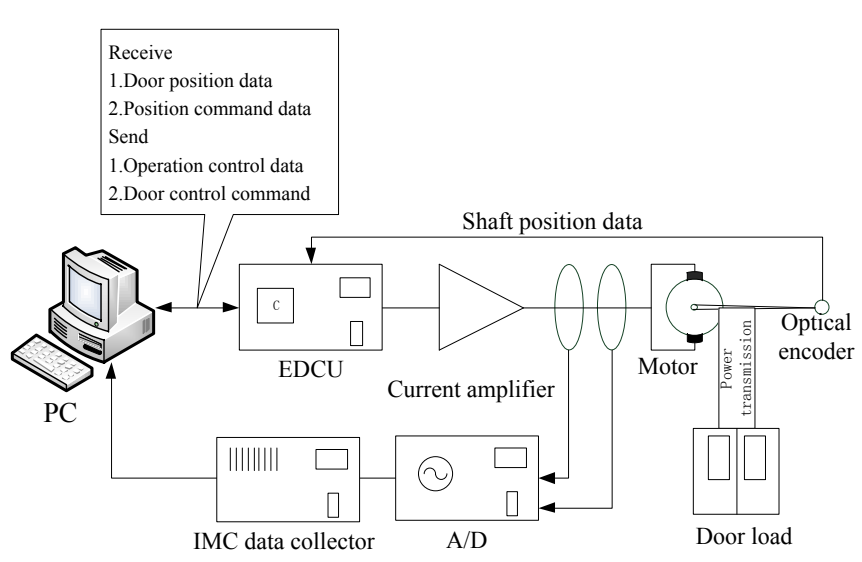

Fig. (4). The passenger door test rig.

The formula (4) is formed by two times of piecewise integral

$\Gamma_{2} y(k)=b_{21} \Gamma_{0} i(k)-a_{1} \Gamma_{1} y(k)+b_{22} \Gamma_{0} d(k)+\operatorname{err}(k)$
$\Gamma_{2} y(k)=\phi^{T}(k) \theta+\operatorname{err}(k)$

Among which

$$
\begin{aligned}
& \phi(k)=\left(\Gamma_{0} i(k), \Gamma_{1} y(k), \Gamma_{0} d(k)\right)^{T} \\
& \theta=\left(b_{21},-a_{1}, b_{22}\right)^{T} \\
& b_{21}=\frac{K_{e}}{J}, a_{1}=\frac{\alpha^{\prime}}{J}, b_{22}=\frac{\beta}{J}
\end{aligned}
$$

For the integral time constant $\Gamma_{i}(i=0,1,2), \operatorname{err}(k)$ is in higher order than the integral window. When the sampling interval is short enough, it can be regarded as a constant or can be ignored, and $K_{e}$ is considered known. The physical parameters of the passenger compartment door can be calculated as follows:

$$
J=\left(\frac{1}{b_{21}}\right) K_{e}, \alpha^{\prime}=\left(\frac{a_{1}}{b_{21}}\right) K_{e}, \beta=\left(\frac{b_{22}}{b_{21}}\right) K_{e}
$$

$\phi(k)$ is the discrete signal piecewise integrated by linear integral filter LIF (Linear Integral Filter). It can be seen that the output of LIF is a linear signal and recursive least square method with fast convergence rate is used to estimate parameters in time domain (RLS) [12], while the real-time physical parameters of the door can be obtained.

For the differentiation of parameter estimates of dimension and size, the obtained parameter estimates ratio data offset was chosen as the criterion of fault detection, as shown in Table 2. The calculation method is the offset divided by the normal data of parameter estimation. 
Table 2. The door fault detection features.

\begin{tabular}{|c|c|}
\hline Attributes & Description \\
\hline \hline$R_{J_{C}}$ & Standardized moment of inertia data of closing door \\
\hline$R_{\alpha_{C}^{\prime}}$ & Standardized moment of dynamic friction torque of closing door \\
\hline$R_{\beta_{C}}$ & Standardized moment of static friction force of closing door \\
\hline$R_{J_{O}}$ & Standardized moment of inertia data of opening door \\
\hline$R_{\alpha_{O}^{\prime}}$ & Standardized moment of dynamic friction torque of opening door \\
\hline$R_{\beta_{O}}$ & Standardized moment of static friction force of opening door \\
\hline
\end{tabular}

\subsection{Fault Detection Algorithm}

Principal component analysis based fault detection method can transform multi variable sample spaces into principal component variables, which are a lower dimensional projection subspace and a corresponding residual subspace. The structure can reflect the spatial variation of the statistics in two spaces respectively,. The observation vector is projected to two subspaces, and the corresponding statistic index is calculated for process monitoring. S. Joe Qin et al. [13, 14] carried out fruitful work regarding the fault diagnosis method based on PCA, such as the optimization index, the optimal number of principal components method etc. Without considering the main element selection, fault detection algorithm of PCA can be realized according to the following three steps.

Step 1. Data normalization for door fault feature

With no fault, door parameter can be obtained after $\mathrm{N}$ times sampling to data matrix $X \in R^{N \times 6}$. Conducting standard treatment to $X$, having the mean value as 0 , variance of 1 sequence of multivariate data in a standardized way can be as follows:

$r_{i}=\frac{x_{i}-x_{\text {mean }}}{x_{\text {std }}}$

For the raw data, $x_{i}$ is the i time sampling value, $x_{\text {mean }}$ is the average of the original data, $x_{\text {std }}$ is the variance of the original data, $r_{i}$ is for the standardized data. Data matrix normalizing is represented for:

$R=\left[\begin{array}{c}r_{1}^{T} \\ \vdots \\ r_{N}^{T}\end{array}\right] \in R^{N \times m}$

Step 2. Decomposition of covariance matrix

The covariance matrix is

$\sum_{0} \approx \frac{1}{N} R^{T} R$
By doing SVD (singular value decomposition) or EVD (SVD), covariance matrix can be decomposed into the following form:

$$
\begin{aligned}
& \frac{1}{N} R^{T} R=P \Lambda P^{T} \\
& \Lambda=\left[\begin{array}{cc}
\Lambda_{p c} & 0 \\
0 & \Lambda_{\text {res }}
\end{array}\right]
\end{aligned}
$$

Use $\sigma_{i}^{2}, i=1,2, \cdots, m$ representing the ith singular value of the covariance matrix, we can get

$$
\begin{aligned}
& \Lambda_{p c}=\operatorname{diag}\left(\begin{array}{lll}
\sigma_{1}^{2} & \cdots & \sigma_{l}^{2}
\end{array}\right) \\
& \Lambda_{r e s}=\operatorname{diag}\left(\begin{array}{ccc}
\sigma_{l+1}^{2} & \cdots & \sigma_{m}^{2}
\end{array}\right) \\
& \sigma_{1}^{2} \geq \cdots \geq \sigma_{l}^{2}>>\sigma_{l+1}^{2} \cdots \geq \sigma_{m}^{2}, P P^{T}=I_{m \times m} \\
& {\left[\begin{array}{c}
P_{p c}^{T} \\
P_{r e s}^{T}
\end{array}\right]\left[\begin{array}{ll}
P_{p c} & P_{r e s}
\end{array}\right]=\left[\begin{array}{cc}
I_{l \times l} & 0 \\
0 & I_{(m-l) \times(m-l)}
\end{array}\right]}
\end{aligned}
$$

Step 3. Online fault detection

When the door completes an opening or closing procedure, new data can be obtained for the door operation. Firstly, by doing standardization, the data $y \in R^{m}$ can be obtained. In this way, the fault detection index can be obtained by the following formula.

$$
\begin{gathered}
S P E=y^{T} P_{r e s} P_{r e s}^{T} y \\
T^{2}=y^{T} P_{p c} \Lambda P_{p c}^{T} y
\end{gathered}
$$

By assuming that fault threshold for SPE and $T^{2}$ are $J_{t h, S P E}$ and $J_{t h T^{2}}$, then the corresponding threshold for SPE with a degree of confidence $\alpha[15]$ is

$$
J_{t h, S P E}=\theta_{1}\left[\frac{h_{0} c_{a} \sqrt{2 \theta_{2}}}{\theta_{1}}+1+\frac{\theta_{2} h_{0}\left(h_{0}-1\right)}{\theta_{1}^{2}}\right]^{1 / h_{0}}
$$


where in $\theta_{i}=\sum_{j=i+1}^{m} \lambda_{j}^{i}, i=1,2,3, \lambda_{i}$ is the ith singular value of a covariance matrix.

The corresponding confidence threshold for $T^{2}$ with a degree of confidence $\alpha[16]$ is

$$
J_{t h, T^{2}}=\frac{(m-l)\left(N^{2}-1\right)}{N(N-m+l)} F_{m-l, N-m+l ; \alpha}
$$

Wherein $F_{m-l, N-m+l ; \alpha}$ is the probability density distribution function $\mathrm{F}$ with a degree of belief $\alpha$, freedom $m-1$ and $N-m+1$

The available fault diagnosis rules are as follows:

$$
\left\{\begin{array}{l}
S P E \leq J_{t h, S P E} \text { AND } T^{2} \leq J_{t h, T^{2}} \rightarrow \text { No fault } \\
\text { Otherwise } \rightarrow \text { Fault }
\end{array}\right.
$$

In actual application of two kinds of evaluation indexes, the sensitivities are not identical, and in the actual test, the use of square prediction error is found to have a higher sensitivity. This article has made use of the index as the basis for judging the fault.

\section{FAULT DIAGNOSIS BASED ON ROUGH SET}

A. Fault recognition method based on Rough Set

Rough set theory was proposed by Poland scholar Z. Pawlak in 1982; its characteristics are as follows [17]:

1. It can handle a variety of data, including incomplete data and data with multi variables;

2. It can deal with imprecise data, including deterministic and non-deterministic situation.

3. It can reveal the simple concept and easy operation mode from the data;

4. It can produce accurate, easy to check and confirmed formation rules, especially rules for intelligent control.

Taking into account the doors' physical parameters changing with fault, the typical door failure always occurs due to mechanical parts damaging caused by aging. For each mode of door parameter weights, in different ways, the usage of PCA based fault detection method can judge whether the fault has occurred. However, for fault identification, as data obtained from the integrator is discrete, numerical calculation results with an inevitable error. Therefore, this paper uses rough set method to detect fault characteristics of the train doors.

Rough set knowledge representation methods exist in the form of decision table. Where in

$U:$ A finite set of objects;

$A$ : The finite set of attributes, $A=C \bigcup D, C$ is the condition attribute subset, $D$ is the decision attribute subset;

$V: V=\bigcup_{p \in A} V_{p}$ is the domain of attribute $P$; $f: U \times A \rightarrow V$ is a total function, s.t. $\forall x_{i} \in U, q \in A$, $f\left(x_{i}, q\right) \in V_{q}$ 。

By applying derivation to formula (2), we get

$$
\left(P^{\prime}(t)\right)^{\prime}=L_{a} \frac{d^{2} i(t)}{d(t)} i(t)+L_{a}\left(\frac{d i(t)}{d(t)}\right)^{2}+K_{e} \omega(t) \frac{d i(t)}{d(t)}
$$

Numerical differentiation is used to obtain each sampling points' derivative, namely the power change rate. By conducting arc tangent to the absolute value of the change rate, sample points' angle to the horizontal plane can be obtained. Moreover, the angle of discrete data can be divided based on discrete degree, collecting the sample data scattered in various areas as condition attributes subset. Then it can be found out whether there is a great relationship between the discrete degree of accuracy and fault recognition. Too small discrete degree results in insignificant fault isolation, while too large difficulty generates effective fault judgment rule and reduced fault separation accuracy. Condition attributes of train door are continuous and there is a need to discretize these attributes to conduct attribute reduction. There are many discretization methods in rough set attribute reduction [18], as dynamic clustering algorithm is chosen for continuous attributes discretization with more reasonable and effective performance.

The decision attributes in the decision table set $D$ are shown in Table $\mathbf{3}$.

Table 3. Decision attribute of train door fault diagnosis.

\begin{tabular}{|c|c|}
\hline Attribute & Description \\
\hline \hline$F(1)$ & Roller failure \\
\hline$F(2)$ & Drive nut fault \\
\hline
\end{tabular}

Door fault identification algorithm is as follows.

Step 1: Acquire screw speed and current signals at different operating conditions.

Step 2: Apply three order spline interpolation to current to obtain numerical differential signal.

Step 3: Get the motor power changing rate

Step 4: Calculate the angle of changing rate with the horizontal axis, and carry out classification to equal angle.

Step 5: Use the dynamic hierarchical clustering method for object classification of finite sets into 3 discrete series.

Step 6: Conduct attribute reduction and generate fault recognition rules.

The first five steps of passenger door fault recognition method are same for the fault recognition rules generation algorithm while the remaining steps are as follows.

Step 1: Generate discrete dynamic hierarchical clustering method according to the sample conditions attributes; 
Step 2: Judge fault mode according to the fault diagnose rules generation algorithm.

B. Algorithm for fault diagnosis

Urban rail train passenger door fault diagnosis algorithm can be summarized as follows data.

Step 1: Generate fault judgment rule based on sample

Step 2: Use PCA based fault detection methods for fault detection initial conditions.

Step 3: When fault is detected, use passenger door fault recognition method for fault identification.

\section{RESEARCH AND ANALYSIS OF EXPERIMENTAL SIMULATION}

In order to simulate the actual working environment, the experimental platform is set with the structure as shown in Fig. (5). With TektronixTPS2014 oscilloscope (Fig. 5a) and IMC-Cronos-PL3 (Fig. 5b), resolved data can be obtained initially. The German company IMC modular number is used for data acquisition, data pretreatment, and data transmission. The screw rod motor test bench and signal processing acquisition unit are shown in Fig. (6). Passenger door experiment appearance is shown in Fig. (7).

(A)

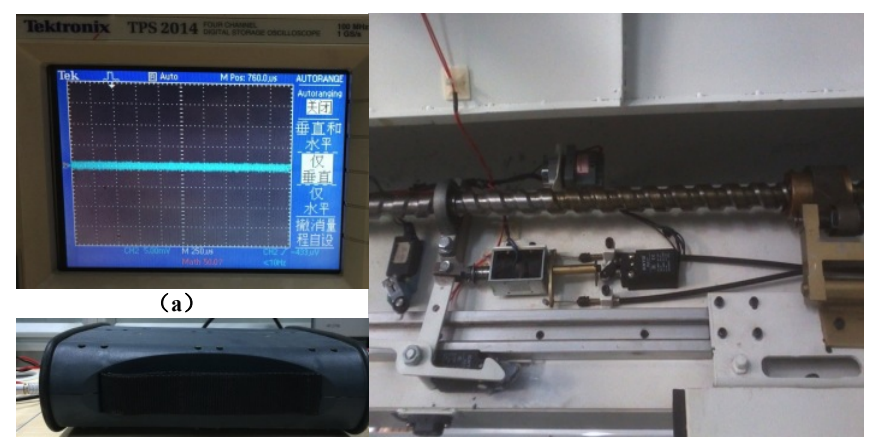

Fig. (5). The picture of passenger door experiment platform.

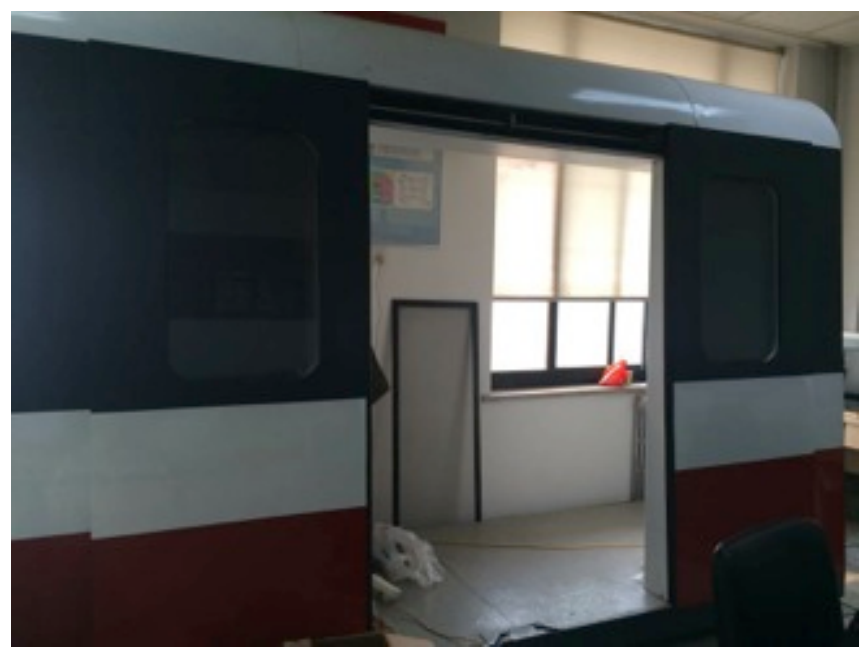

Fig. (6). Outside view of passenger door experimental platform.

With the signal sampling interval $T_{0}=4096 \mu \mathrm{s}$, when the 3 seconds open configuration is used after normalization of a normal case closing procedure, signals are as shown in Fig. (8).

It can be seen from the chart that the passenger door working process is divided into three sections, respectively as accelerating, decelerating and stable operation period. The peak of signals occurs in the process of opening end stage and the door closing start stage. It can be inferred from the two figures that further the distance between the door frame and lead screw, particularly the motor, the larger the motor damping torque. This phenomenon is caused by the process of lubrication and load imbalance or screw problem.

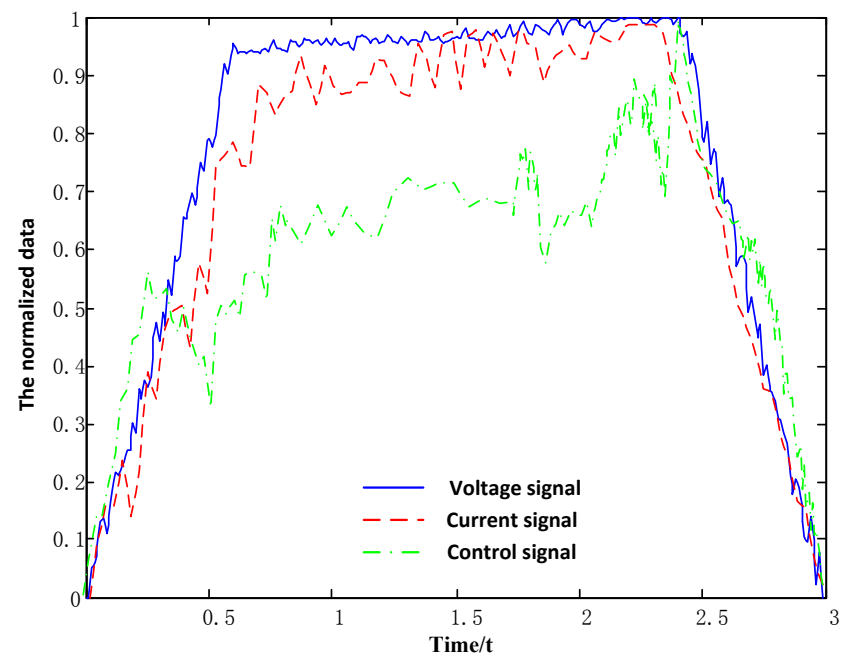

Fig. (7). Normalized signal of door opening procedure.

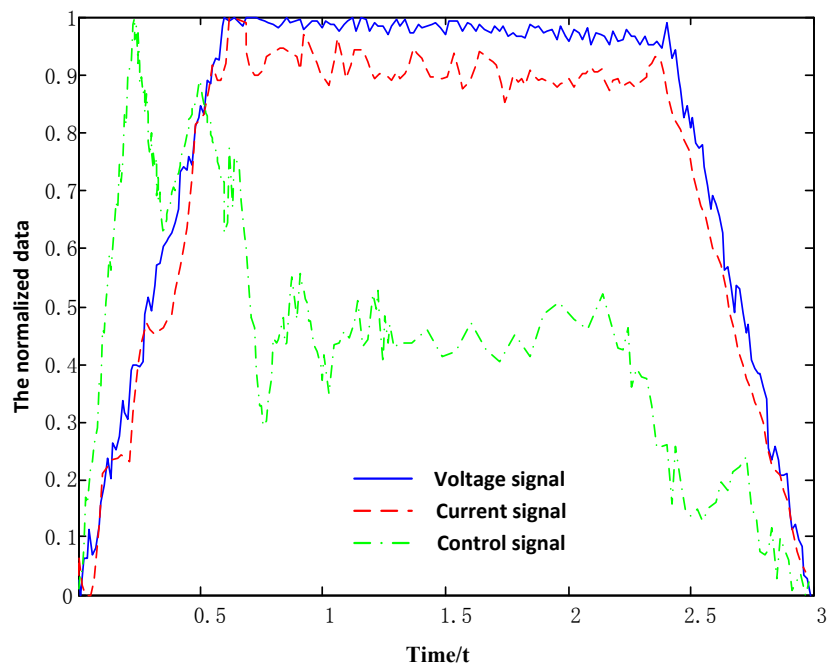

Fig. (8). Normalized signal of door closing procedure.

Attention should be paid that the passenger door only works in the train station and there is no need to consider the efficiency of computer operation in the process of failure diagnosis, thus the sampling interval for fault diagnosis can be reduced to obtain more precise parameter estimation and fault diagnosis results.

In consideration that there are more acceleration and deceleration sections of the dynamic information, the stable operation period $(0.8-2.2 \mathrm{~s})$ can be selected for parameter 
Table 4.

\begin{tabular}{|c|c|c|c|c|}
\hline \multicolumn{2}{|r|}{ Fault Mode } & Normal & Roller Failure & Drive Nut Fault \\
\hline \hline$J_{c}$ & $\mathrm{kgm}^{2}$ & 0.00643 & 0.00741 & 0.00844 \\
\hline$\alpha_{\mathrm{c}}^{\prime}$ & $\mathrm{Nm}$ & & 0.0080 & 0.0041 \\
\hline$\beta_{\mathrm{c}}$ & $(\mathrm{rad} \mathrm{s})^{-1}$ & 0.0056 & 1.681 & 1.370 \\
\hline$J_{\mathrm{o}}$ & $\mathrm{Nm}$ & 1.272 & 0.00771 & 0.00443 \\
\hline$\alpha_{\mathrm{o}}^{\prime}$ & $\mathrm{kgm}$ & 0.00785 & 0.0067 & 0.0039 \\
\hline$\beta_{\mathrm{o}}$ & $(\mathrm{rad} \mathrm{s})^{-1}$ & 0.0038 & 1.63 & 1.31 \\
\hline
\end{tabular}

estimation. With sampling interval of $T_{0}=256 \mu \mathrm{s}$, the 3 conditions of 20 simulation trials were averaged with the door opening procedure, with integral window 20 times of the sample rate. The door opening and closing procedure estimation of the physical parameters is shown in Table 4.

The physical parameters are specified for fault detection, $J_{c}, \alpha_{\mathrm{c}}^{\prime}, \beta_{\mathrm{c}}$ as the fault detection sequence when the door is closing, $J_{\mathrm{o}}, \alpha_{\mathrm{o}}^{\prime}, \beta_{\mathrm{o}}$ when the door is closing, using PCA based fault detection algorithm.

During the procedure of rough set based fault identification, the sample data set number of each failure mode choice should be moderate, as the selection of too many groups may result in too little fault identification rules while too little groups can cause the judgment rule inaccurate. Through repeated tests, when the discrete degree is 10,3 groups of motor power changing rate angle classification data for each condition can be selected, acquiring the best results. According to the 9 objects composed finite set of opening procedure in $3 \mathrm{~S}$ conditions, through the dynamic hierarchical clustering algorithm[19] on the change rate of power angle classified data, discretized decision table is shown in Table 5.

Before the generation of fault judgment rules, the fault data are selected as condition attributes for reduction and rules generation, so that the recognition rate is improved.

According to the attribute reduction for condition attributes which is shown in Table 2, 4 reductions are obtained for door fault diagnosis, $\left\{A_{0}, A_{2}\right\},\left\{A_{2}, A_{4}, A_{7}\right\},\left\{A_{2}, A_{3}, A_{6}, A_{7}\right\}$, $\left\{A_{1}, A_{2}, A_{3}, A_{7}\right\}$. By conducting attributes reduction, fault diagnosis rules can be generated separately for each attribute reduction set and the fault isolating rules can be obtained as shown in Table 6.

Simulating three kinds of working statuses to the door in the 4 opening/closing duration profiles, 50 times each working scheme is carried out. The testing accuracy of the statistical results is shown in Table 7.

Table 5. Discretized decision table.

\begin{tabular}{|c|c|c|c|c|c|c|c|c|c|c|c|}
\hline \multirow{2}{*}{ Sample } & \multicolumn{10}{|c|}{ Condition Attribute } & \multirow{2}{*}{$\frac{\text { Fault Type }}{F}$} \\
\hline & $A_{0}$ & $A_{1}$ & $A_{2}$ & $A_{3}$ & $A_{4}$ & $A_{5}$ & $A_{6}$ & $A_{7}$ & $A_{8}$ & $A_{9}$ & \\
\hline 2 & 1 & 1 & 1 & 1 & 1 & 1 & 2 & 1 & 3 & 3 & 0 \\
\hline 3 & 1 & 1 & 1 & 1 & 2 & 1 & 2 & 2 & 3 & 3 & 0 \\
\hline 5 & 1 & 1 & 1 & 1 & 3 & 2 & 3 & 2 & 3 & 3 & 1 \\
\hline 6 & 1 & 2 & 1 & 2 & 3 & 2 & 2 & 2 & 3 & 3 & 1 \\
\hline 7 & 2 & 1 & 1 & 2 & 2 & 2 & 3 & 2 & 3 & 3 & 2 \\
\hline 8 & 2 & 1 & 1 & 1 & 3 & 2 & 2 & 1 & 3 & 3 & 2 \\
\hline 9 & 1 & 2 & 2 & 2 & 3 & 2 & 2 & 2 & 3 & 3 & 2 \\
\hline
\end{tabular}


Table 6. Fault inference rules.

\begin{tabular}{|c|c|c|}
\hline Rule Number & Rules & Inference \\
\hline Rule1 & A0(1) AND A2(1) & $\mathrm{F}(1)$ \\
\hline Rule2 & $\mathrm{A} 0(2) \mathrm{AND}$ A2(1) & $\mathrm{F}(2)$ \\
\hline Rule3 & A0(1) AND A2(2) & $\mathrm{F}(2)$ \\
\hline Rule4 & A2(1) AND A4(3) AND A7(2) & $\mathrm{F}(1)$ \\
\hline Rule5 & A2(1) AND A4(2) AND A7(2) & $\mathrm{F}(2)$ \\
\hline Rule6 & A2(1) AND A4(3) AND A7(1) & $\mathrm{F}(2)$ \\
\hline Rule7 & A2(2) AND A4(3) AND A7(2) & $\mathrm{F}(2)$ \\
\hline Rule8 & A2(1) AND A3(1) AND A6(2) AND A7(2) & $\mathrm{F}(1)$ \\
\hline Rule9 & A2(1) AND A3(1) AND A6(3) AND A7(2) & $\mathrm{F}(1)$ \\
\hline Rule10 & A2(1) AND A3(2) AND A6(2) AND A7(2) & $\mathrm{F}(1)$ \\
\hline Rule11 & A2(1) AND A3(2) AND A6(3) AND A7(2) & $\mathrm{F}(2)$ \\
\hline Rule12 & A2(1) AND A3(1) AND A6(2) AND A7(1) & $\mathrm{F}(2)$ \\
\hline Rule13 & A2(2) AND A3(2) AND A6(2) AND A7(2) & $\mathrm{F}(2)$ \\
\hline Rule14 & A1(1) AND A2(1) AND A3(1) AND A7(2) & $\mathrm{F}(1)$ \\
\hline Rule15 & A1(2) AND A2(1) AND A3(2) AND A7(2) & $\mathrm{F}(1)$ \\
\hline Rule16 & A1(1) AND A2(1) AND A3(2) AND A7(2) & $\mathrm{F}(2)$ \\
\hline Rule17 & A1(1) AND A2(1) AND A3(1) AND A7(1) & $\mathrm{F}(2)$ \\
\hline Rule18 & A1(2) AND A2(2) AND A3(2) AND A7(2) & $\mathrm{F}(2)$ \\
\hline
\end{tabular}

Table 7. Statistics of testing accuracy.

\begin{tabular}{|c|c|c|c|}
\hline O/C Time & Normal & F(1) & F(2) \\
\hline \hline 2.5 & $82 \%$ & $78 \%$ & $82 \%$ \\
\hline 3.0 & $93 \%$ & $86 \%$ & $91 \%$ \\
\hline 3.5 & $100 \%$ & $92 \%$ & $93 \%$ \\
\hline 4.0 & $100 \%$ & $92 \%$ & $96 \%$ \\
\hline Average & $93.75 \%$ & $87 \%$ & $90.5 \%$ \\
\hline
\end{tabular}

As can be seen, for the two kinds of fault, the longer opening and closing duration makes the door fault judgment and fault recognition more accurate, so it is more efficient if long model is chosen for fault diagnosis on urban rail train electric door, however the common 3 seconds factory configuration can basically meet the demand of fault diagnosis. From the average recognition ratio, it can be seen that the use of PCA fault diagnosis method can meet the demand of fault detection for different fault levels. When failure analysis is conducted on experimental platform as shown, fault recognition is accurate for wire rod and a driving nut is more precise than that for roller, guide rail, so if it is hard to confirm the fault situation, then it can be checked on later.

\section{CURRENT \& FUTURE DEVELOPMENTS}

The research of fault diagnosis for urban rail train door is a weak field both home and abroad. This paper showed a real-time fault diagnosis method for urban rail train doors. First of all, the working process was introduced for the train doors, respectively from the door opening and closing movement and the mathematical model was established for the door motor working angle. For the electrodynamic model, integral filter circuit was used for signal preprocessing, and the parameter estimation method was used to obtain the door physical parameters. In order to realize the real-time fault diagnosis, the influence of fault was considered through fault recognition, and PCA based method was proposed for fault detection. Then, the rough set based method was used for fault diagnosis. Through the experiment on the test rig, the accuracy of this method was verified. Compared with the traditional off-line fault diagnosis methods based on probability theory and mathematical statistics, this method can prove to be more real-time effective for urban rail trains' passenger doors' real-time monitoring. 


\section{CONFLICT OF INTEREST}

The authors confirm that this article content has no conflict of interest.

\section{ACKNOWLEDGEMENTS}

This work was supported in part by The National High Technology Research and Development Program of China (Grant No. 2012AA112001-07).

\section{REFERENCES}

[1] F. Sheng-Wei, S. Yu, and S. Hui-Chao, "Construction and application of Bayesian networks based on fault analysis model", Jisuanji Jicheng Zhizao Xitong, vol. 9, pp. 1768-1773, 2007.

[2] Z. Xiaojuan, W. Jianbing, and Y. Zhenmin, "On the reliability of passenger compartment door in shanghai metro trains", Urban Mass Transit, vol. 3, pp. 31-34, 2006.

[3] D. Junzhe, Y. Jianwei, and H. Qiang, "Reliability analysis of passenger compartment door of metro vehicles based on GO Method", Urban Mass Transit, vol. 4, pp. 28-32, 2013.

[4] L. Bihong, H. Peng, F. Zhenliang, and G. Feng, "Case study on FMECA and risk assessment for the door system in high speed train", Advanced Materials Research. Engineering Solutions for Manufacturing Processes, pp. 2335-2339, 2013.

[5] N. Lehrasab, H. P. Dassanayake, C. Roberts, S. Fararooy, and C. J. Goodman, "Industrial fault diagnosis: pneumatic train door case study", In: Proceedings of the Institution of Mechanical Engineers, Part F: Journal of Rail and Rapid Transit. 2002, pp. 175-183.

[6] E. Miguelanez, K.E. Brown, R. Lewis, C. Roberts, and D.M. Lane, "Fault diagnosis of a train door system based on semantic knowledge representation", 4th IET International Conference on Railway Condition Monitoring - RCM 2008. IET, 2008, pp. 27-27.

[7] H. Dassanayake, C. Roberts, C.J. Goodman, and A.M. Tobias. "Use of parameter estimation for the detection and diagnosis of faults on electric train door systems", Proceedings of the Institution of Mechanical Engineers, Part O: Journal of Risk and Reliability, vol. 4, pp. 271-278, 2009.

[8] H. Xiaoyan, C. Zuguo, and W. Jianbin, "Time-domain analysis on shanghai metro train door failure", Urban Mass Transit, vol. 7, 2012

[9] C. Hao, "Modeling and Simulation of ball screw dynamic analysis based on MATLAB", Gansu Science and Technology, vol. 23, pp. 130-132, 2007

[10] W. Songtao, H. Fenghua, and D. Feng, "Linear approximating method in the transacting process of nonlinear standardization of data", Journal of Information Engineering University, vol. 8, pp. 250-253, 2007

[11] D. Xiaoying, J. Zhenshan, W. yong, L. Shi, "Design of serfadapting intelligent integrator", Computer Engineering and Applications, vol. 45, pp. 85-87, 2009.

[12] C. Zheming, Z. Jing, and L. Ren, "Wheel-slip prevention control and simulation under train pneumatic braking", Journal of the China Railway Society, (4), pp. 25-31, 2009.

[13] S. J, Qin, "Statistical process monitoring: basics and beyond", Journal of Chemometrics, vol. 17(8-9), pp. 480-502, 2003.

[14] S. J. Qin, and R. Dunia, "Determining the number of principal components for best reconstruction", Journal of Process Control, vol. 10(2), pp. 245-250, 2000

[15] W. Li, H. H. Yue, and S. Valle-Cervantes, et al., "Recursive PCA for adaptive process monitoring", Journal of process control, vol. 10, pp. 471-486, 2000

[16] J. E. Jackson, and G. S. Mudholkar, "Control procedures for residuals associated with principal component analysis", Technometrics, vol. 21, pp. 341-349, 1979.

[17] Q. Tian, D. Yanjun, and W. Zhansong, "Sensor fault detection statistics based on principal component analysis", Journal of Tsinghua University (Science and Technology), vol. 46, pp. 14471450, 2006.

[18] H. Zhenxiang, Z. Qi, and W. Fushuan, "Rough Sets: Theory and Application", Information and Control, vol. 27, pp. 37-45, 1998.

[19] L. Xiaofei, "On discretization algorithm based on dynamic hierarchical clustering", Coumputer Applications and Software, vol. 26 , pp. $262-264,2009$ 